\title{
Sleep Disruption and Gestational Diabetes
}

\author{
Francesca Facco ${ }^{*}$
}

Magee-Womens Hospital, Department of Obstetrics and Gynecology, 300 Halket Street, Room 2233, Pittsburgh, PA 15213, USA

\begin{abstract}
Numerous studies in non-pregnant populations have demonstrated associations between sleep disturbances and a broad range of medical conditions including type 2 diabetes. Data exploring the relationship between sleep and adverse pregnancy outcomes are now emerging. This review will summarize the literature regarding sleep duration and sleep disordered breathing during pregnancy and its potential impact on maternal glucose metabolism.
\end{abstract}

Keywords: Sleep, short sleep duration, sleep disordered breathing, pregnancy, gestational diabetes.

\section{INTRODUCTION}

Overall, women have a greater risk for sleep disorders than do men, and complaints of sleep disturbance are more prevalent among women than men across the life span. Pregnancy has been associated with several alterations in sleep and a high incidence of sleep disturbances [1]. Many of the hormonal and physiological changes that occur during pregnancy have been linked to alterations in sleep.Sleep, like nutrition and exercise is an essential component of a healthy lifestyle. Numerous studies in non-pregnant populations have demonstrated associations between sleep disturbances and a broad range of medical conditions including type 2 diabetes.Data exploring the relationship between sleep and adverse pregnancy outcomes are now emerging.

The possibility that sleep abnormalities are associated with pregnancy complications is biologically plausible. First, data suggests that sleep disorders are prevalent in early pregnancy, and pregnancy itself has been linked to alterations in sleep [1-4]. Second, disturbed sleep is associated with autonomic dysfunction, inflammation, oxidative stress, metabolic dysregulation, endothelial dysfunction and inflammation [5-11]. These same pathophysiologic mechanisms have been implicated in the pathogenesis of adverse pregnancy outcomes, including gestational diabetes [12-14]. This review will summarize the literature regarding sleep disruption during pregnancy and its potential impact on maternal glucose metabolism.

\section{SLEEP AND GLUCOSE METABOLISM IN NON- PREGNANT POPULATIONS}

Studies of experimental sleep deprivation and sleep fragmentation have linked these sleep alterations with impairments in metabolic function. Spiegel et al compared measurements of carbohydrate metabolism in healthy

*Address correspondence to this author at the Magee-Womens Hospital, Department of Obstetrics and Gynecology, 300 Halket Street, Room 2233, Pittsburgh, PA 15213, USA; Tel: 412-641-5406; Fax: 412-641-1133; E-mail: faccof@upmc.edu subjects who were restricted to 4 hours in bed per night with measurements taken at the end of a sleep-recovery period. They found that glucose clearance was $40 \%$ slower in the sleep debt condition than in the sleep recovery condition [15]. In a recent study, using an experimental model of sleep fragmentation, levels of insulin sensitivity and glucose effectiveness were shown to decrease in the sleep fragmented state [16]. Similarly, epidemiologic studies have consistently demonstrated an association between shortened sleep duration and metabolic disease [17-23]. Reports from several large cohort studies suggest a relationship between sleep duration (self-reported and objectively assessed) and impaired glucose tolerance and type 2 diabetes. Data from the Sleep Heart Health Study suggest that compared to individuals sleeping 7-8 hours/night, individuals sleeping $\leq 5$ hours/night or less than 6 hours/night have an adjusted odds ratio for diabetes of 2.51 and 1.66, respectively [20]. Although the greater part of the evidence points to an association between short sleep and diabetes, a few reports have also described an association between long sleep ( $\geq 9$ hours) and diabetes risk [24, 25].

Sleep disordered breathing (SDB) has also been associated with metabolic dysfunction. SDB refers to a group of disorders characterized by abnormal respiratory patterns (e.g., apneas, hypopneas) or abnormal gas exchange (e.g., intermittent hypoxia) during sleep [26, 27]. SDB is clinically characterized by the presence of respiratory disturbances observed during a sleep study. It is most commonly diagnosed using the Apnea Hypopnea Index (AHI), a sum of the number of apneas and hypopneas that occur per hour of sleep.In adults an AHI of 0-4.9 is considered normal, with an AHI of $\geq 5$ defining SDB. An AHI of 5-15 is typically considered mild SDB, 15-30 moderate SDB, and $>30$ as severe SDB [26, 27]. The most common type of SDB, especially among young obese women, is obstructive sleep apnea (OSA) which is characterized by repetitive episodes of nocturnal upper airway obstruction. Mouse models of intermittent hypoxia have been developed that mimic the oxygen profile in human OSA. Data from such models have demonstrated that intermittent hypoxia can cause acute insulin resistance in 
Table 1. Subjective Short Sleep Duration and Gestational Diabetes Risk

\begin{tabular}{|c|c|c|c|c|c|}
\hline Study & N & $\begin{array}{c}\text { Population } \\
\text { Description }\end{array}$ & $\begin{array}{c}\text { Definition of Short } \\
\text { Sleep Duration }\end{array}$ & $\begin{array}{c}\text { Odds Ratio or } \\
\text { Relative Risk (95\% } \\
\text { Confidence Intervals }\end{array}$ & $\begin{array}{c}\text { Adjusted Odds Ratio or } \\
\text { Relative Risk (95\% } \\
\text { Confidence Intervals) }\end{array}$ \\
\hline \hline Facco et al., 2010 & 189 & $\begin{array}{c}\text { Healthy nulliparous } \\
\text { women with singleton } \\
\text { gestations }\end{array}$ & $<7$ hours/night & $10.6(1.3,85.5)$ & $11.7(1.2,114.5)^{*}$ \\
\hline Qiu et al., 2010 & 1,290 & $\begin{array}{c}\text { Pregnant women } \\
\text { without pre-gestational } \\
\text { diabetes }\end{array}$ & $\leq 4$ hours/night & $5.56(1.3,23.7)$ & $4.18(0.94,18.60)^{* *}$ \\
\hline Reutrakul, et al., 2011 & 169 & $\begin{array}{c}\text { Healthy pregnant } \\
\text { women }\end{array}$ & $<7$ hours/night & $2.4(1.0,5.9)$ & N/A \\
\hline
\end{tabular}

*adjusted for age, race/ethnicity, BMI and snoring

**adjusted for age, race/ethnicity, and BMI

$\mathrm{N} / \mathrm{A}=$ not reported

otherwise lean, healthy mice and that it exacerbates the metabolic effects of diet-induced obesity [28, 29]. Epidemiologic data supports an association between sleep apnea and type 2 diabetes [30-33]. Cross-sectional data from the Wisconsin Sleep Cohort Study demonstrated that selfreported diabetes was three to four times more prevalent in subjects with an AHI $\geq 15$ than in those with an AHI $<5$ [32]. One large longitudinal investigation demonstrated that moderate-severe sleep apnea was an independent risk factor for incident diabetes in an Australian population-based cohort [30]. Recently, Aronsohn and colleagues looked at the impact of untreated OSA on glucose control in type 2 diabetes and found that increasing severity of OSA is associated with poorer glucose control, independent of adiposity and other confounders, with effect sizes comparable to those of widely used hypoglycemic drugs [34].

\section{GESTATIONAL DIABETES}

Maternal metabolic physiology during pregnancy, especially in the third trimester, is primarily influenced by placental hormones. These hormones affect both glucose and lipid metabolism with the goal of providing the growing fetus with an ample supply of nutrients at all times. Carbohydrate metabolismduring pregnancy is directed toward supplying glucose and amino acids to the fetus, while providing extra free fatty acids, ketones, and glycerol as sources of maternal fuel [35, 36]. Physiologic changes during normal pregnancy include: hyperplasia of the insulinsecreting pancreatic beta cells, increased insulin secretion, and progressive insulin resistance. These changes result in transient maternal hyperglycemia after meals due to increasing insulin resistance and transient hypoglycemia between meals and at night due to the continuous fetal uptake. The insulin resistant state of pregnancy exists to support the demands of the growing fetus however, it can become pathological when a women's pancreatic function is not sufficient to overcome this new metabolic state [37].

Gestational diabetes mellitus (GDM), defined as glucose intolerance that begins or is first recognized during pregnancy, affects $1-14 \%$ of all pregnancies [38]. Almost uniformly, GDM arises from significant maternal insulin resistance. Screening for GDM is usually done by first performing a 50 gram, 1-hour oral glucose tolerance test (OGTT). If this 1 -hr OGTT test is abnormal ( $\geq 130$ or 140 $\mathrm{mg} / \mathrm{dL}$ cut-off values are typically used) then a fasting 3hour, 100 gram OGTT test is used to diagnose GDM using either the National Diabetes Data Group or CarpenterCoustan diagnostic thresholds [38]. Gestational diabetes has been associated with an increased risk of preeclampsia, fetal macrosomia, birth trauma, and neonatal metabolic complications that often require admission to the neonatal intensive care unit (hypoglycemia, hyperbilirubinemia, hypocalcemia). There are also potential long-term consequences to infants born to mothers with GDM, such as an increased risk of developing obesity and diabetes during childhood [39]. Traditionally recognized risk factors for gestational diabetes include: advanced maternal age, obesity, family history of type 2 diabetes, membership in a racialethnic group with a high background rate of type 2 diabetes (e.g., Hispanic-American, AfricanAmerican, Native American), and a personal history of chronic hypertension. Recently, given the emerging evidence regarding sleep, sleep disruption and metabolic dysregulation, interest has emerged in evaluating whether poor sleep during pregnancy may impact maternal glucose metabolism.

\section{SLEEP DURATION AND GESTATIONAL DIABETES}

Several investigators have now reported a positive association between self-reported short sleep duration and gestational diabetes (Table 1) [40-42]. The data suggests that women with self-reported shortened sleep durations during pregnancy have a 2-10 times greater risk of GDM . Facco et al and Qiu et al found that the risk of GDM remained even after controlling various confounding factors including body mass index (BMI) [40, 41]. In addition, Qiu et al described a curvilinear relationship between maternal habitual nightly sleep duration in early pregnancy and maternal mean 1-hr OGTT values. Mean glucose concentrations were 16.3 $\mathrm{mg} / \mathrm{dL}$ higher in women who reported sleeping $\leq 4$ hours per night (95\% CI 1.1, 31.6), $2.3 \mathrm{mg} / \mathrm{dLhigher} \mathrm{(95 \%} \mathrm{CI} \mathrm{-1.8,}$ 6.3 ) for women reporting sleep durations of 5-8 hours/night and $6.3 \mathrm{mg} / \mathrm{dL}$ higher $(95 \% \mathrm{CI}-0.5,13.2)$ for women who reported sleeping $\geq 10$ hours/night, compared with those who reported sleeping on average 9 hours/night. The obvious 
Table 2. Sleep Disordered Breathing Symptoms and Gestational Diabetes Risk

\begin{tabular}{|c|c|c|c|c|c|}
\hline Study & $\mathbf{N}$ & Population Description & SDB Symptoms & $\begin{array}{l}\text { Odds Ratio or Relative } \\
\text { Risk ( } 95 \% \text { Confidence } \\
\text { Intervals or p Value) }\end{array}$ & $\begin{array}{c}\text { Adjusted Odds Ratio or } \\
\text { Relative Risk (95\% Confidence } \\
\text { Intervals or p Value) }\end{array}$ \\
\hline Facco et al., 2010 & 189 & $\begin{array}{c}\text { Healthy nulliparous } \\
\text { women with singleton } \\
\text { gestations }\end{array}$ & $\begin{array}{l}\text { Frequent snoring } \geq 3 \\
\text { nights/week }\end{array}$ & $4.9(1.3,18.1)$ & $6.9(1.4,33.9)^{*}$ \\
\hline Qiu et al., 2010 & 1,290 & $\begin{array}{l}\text { Pregnant women without } \\
\text { pre-gestational diabetes }\end{array}$ & $\begin{array}{c}\text { Snoring most or all of the } \\
\text { time }\end{array}$ & $1.86(0.88,3.94)$ & $1.54(0.71 .3 .35)^{* *}$ \\
\hline Bourjeily et al., 2010 & 1000 & $\begin{array}{l}\text { Women } 24-48 \text { hours } \\
\text { postpartum }\end{array}$ & $\begin{array}{c}\text { Frequent snoring } \geq 3 \\
\text { night/week } \\
\text { Frequent gasping/snoring } \\
\geq 3 \text { night/week } \\
\text { Frequent } \\
\text { choking/stopping } \\
\text { breathing } \geq 3 \text { night/week }\end{array}$ & $\begin{array}{l}2.7(1.7,4.3) \\
3.3(1.9,5.6) \\
2.6(1.3,5.5)\end{array}$ & $\begin{array}{l}2.1(1.3,3.4)^{\dagger} \\
2.4(1.4,4.3)^{\dagger} \\
2.0(0.9,4.3)^{\dagger}\end{array}$ \\
\hline Olivarez et al., 2011 & 220 & $\begin{array}{l}\text { Healthy nulliparous } \\
\text { women with singleton } \\
\text { gestations }\end{array}$ & $\begin{array}{l}\text { Positive Berlin and/or } \\
\text { Epworth Sleepiness } \\
\text { Scale Score }(\geq 10)\end{array}$ & $0.99(0.98)$ & N/A \\
\hline Reutrakul et al., 2011 & 169 & Healthy pregnant women & $\begin{array}{c}\text { Frequent snoring } \geq 3 \\
\text { nights/week }\end{array}$ & $3.4(1.3,8.8)$ & N/A \\
\hline O’Brien et al., 2012 & 1719 & $\begin{array}{c}\text { Pregnant women with } \\
\text { singleton gestations } \geq 28 \\
\text { weeks }\end{array}$ & $\begin{array}{c}\text { Frequent snoring } \geq 3 \\
\text { nights/week } \\
\text { Chronic (snoring both } \\
\text { before and during } \\
\text { pregnancy) } \\
\text { Pregnancy-onset snoring }\end{array}$ & $\begin{array}{l}1.29(0.96,1.74) \\
1.67(1.10,2.52)\end{array}$ & $\begin{array}{l}0.91(0.55-1.49)^{\ddagger} \\
1.0(0.72,1.39)^{\ddagger}\end{array}$ \\
\hline
\end{tabular}

*adjusted for age, race/ethnicity, BMI and sleep duration

**adjusted for age, race/ethnicity, and BMI

†adjusted for age, BMI, smoking and multifetal gestation

tadjusted for age, race/ethnicity, BMI, smoking, parity and education level

$\mathrm{N} / \mathrm{A}=$ not reported

limitation of the currently available data is the use of selfreported sleep duration as the exposure variable. Self-reports of sleep duration have a reasonable although not exact correlation with objective measures (e.g., actigraphy) of sleep, with self-report generally overestimating objectively measured sleep [43]. Prospective investigations using objective sleep measures are needed to confirm these initial findings regarding the impact of sleep duration on glucose metabolism in pregnancy.

While the majority of the literature has focused on short sleep in pregnancy, there are some data suggesting that long sleep duration can negatively impact glucose metabolism in pregnancy. Qui et al described a curvilinear relationship between habitual nightly sleep duration in early pregnancy and maternal mean-1hour plasma glucose after a 50 gram oral glucose challenge [41]. Compared to women who reported sleeping 9 hours per night on average, mean glucose concentrations were $16.3 \mathrm{mg} / \mathrm{dl}(\mathrm{p}=.04)$ higher for women sleep $\leq 4$ hours per night and $6.3 \mathrm{mg} / \mathrm{dl}(\mathrm{p}=.07)$ higher for women sleeping $\geq 10$ hours per night.

\section{SLEEP DISORDERED BREATHING GESTATIONAL DIABETES}

AND

Several reports have now been published regarding the relationship between sleep-disordered breathing symptoms and gestational diabetes (Table 2) [40-42, 44-46]. Several studies have reported positive associations between frequent snoring, the most common symptom of SDB, and GDM, even after controlling confounding factors, including BMI. Bourjeily et al looked at several SDB symptoms, snoring, gasping/snorting and chocking/stopping breathing, and reported that when all three symptoms were combined the association with GDM was stronger than for any individual symptom (adjusted odds ratio 4.0, 95\% CI 1,4, 11.1) [44]. In contrast, Olivarez et al did not find a positive association or trend between SDB and GDM, even after stratifying by BMI [45]. However, these authors used the Berlin Questionnaire and the Epworth Sleepiness Scale as their measure of SDB. The Berlin Questionnaire and Epworth Sleepiness Scale were designed for and validated in non-pregnant, predominantly male, middle-aged and elderly populations $[47,48]$. Indeed, there is some data suggesting that these tools are not as accurate in pregnancy $[49,50]$.

Again, as with the sleep duration, data using objective measures of SDB are limited. While investigators have demonstrated that self-reported habitual snoring correlates with objective findings on polysomnogram (PSG) [51], studies utilizing objective SDB measures are needed to accurately define the relationship between SDB and adverse pregnancy outcomes. Data regarding the effect of objectively assessed SDB on glucose metabolism in pregnancy are limited, and primarily retrospective $[52,53]$. In one 
retrospective cohort study of women who had a delivery as well as a PSG at a single institution, moderate to severe SDB $(\mathrm{AHI} \geq 15)$ was associated with an increased risk of GDM $(11.5 \%$ vs. $5.8 \%$ in women with mild SDB and $0 \%$ in women without SDB, $\mathrm{p}=0.004$ ) [54]. However, given the sample size, this study was unable to demonstrate a relationship independent of BMI. In the largest retrospective cohort of women with PSG confirmed SDB ( $\mathrm{n}=791)$, Chen at al reported that SDB was associated with an increased risk of GDM (aOR 1.63, 95\% CI 1.07, 2.48). However, this Taiwanese database study lacked BMI data, and the reported obesity rate was only $1.6 \%$ [53].To accurately define the relationship between SDB and adverse pregnancy outcomes like GDM, well designed prospective cohort studies using objective measures of SDB are needed. Another significant issue is that obesity is a well known risk factor for both adverse pregnancy outcomes and SDB and complicates defining a causal relationship between SDB and pregnancy outcomes, particularly metabolic and cardiovascular complications of pregnancy (e.g., gestational diabetes and preeclampsia). Future studies need to be designed and powered to be able to examine the relationship between objectively assessed SDB and adverse pregnancy outcomes, independent of BMI.

\section{SUMMARY}

In summary, several cohort and cross-sectional studies have examined the relationship between self-reported sleep duration and SDB symptoms and pregnancy outcomes and have found associations between shortened sleep duration, snoring and glucose metabolism in pregnancy. However, interpretation of this data is limited given the paucity of objective sleep measures, and inconsistent adjustment for confounding factors such as obesity. Further research, using objective measures of sleep duration and SDB, is needed to better understand how these sleep disturbances modify a woman's risk of adverse pregnancy outcomes. Unlike many other adverse pregnancy outcome risk factors, sleep is potentially modifiable. If future research demonstrates that certain sleep disturbances increase the risk of adverse pregnancy outcomes such as gestational diabetes, the next step would be to design studies to determine whether screening for and treating these disorders can improve maternal and fetal outcomes. This research could lead to significant changes in clinical practice because obstetric care providers currently are not trained to screen for sleep disturbances, and do not routinely refer or treat women who have sleep-related complaints. Additionally, this research can lead to public health recommendations regarding sleep that are specifically targeted towards pregnant women.

\section{CONFLICT OF INTEREST}

The authors confirm that this article content has no conflicts of interest.

\section{ACKNOWLEDGEMENTS}

Declared none.

\section{REFERENCES}

[1] Pien GW, Schwab RJ. Sleep disorders during pregnancy. Sleep 2004; 27(7): 1405-17.
[2] Facco FL, Kramer J, Ho KH, Zee PC, Grobman WA. Sleep disturbances in pregnancy. Obstet Gynecol 2010; 115(1): 77-83.

[3] Sahota PK, Jain SS, Dhand R. Sleep disorders in pregnancy. Curr Opin Pulm Med 2003; 9(6): 477-83.

[4] Santiago JR, Nolledo MS, Kinzler W, Santiago TV. Sleep and sleep disorders in pregnancy. Ann Intern Med 2001; 134(5): 396408.

[5] Jelic S, Le Jemtel TH. Inflammation, oxidative stress, and the vascular endothelium in obstructive sleep apnea. Trends Cardiovasc Med 2008; 18(7): 253-60.

[6] Meerlo P, Sgoifo A, Suchecki D. Restricted and disrupted sleep: effects on autonomic function, neuroendocrine stress systems and stress responsivity. Sleep Med Rev 2008; 12(3): 197-210.

[7] Mullington JM, Haack M, Toth M, Serrador JM, Meier-Ewert HK. Cardiovascular, inflammatory, and metabolic consequences of sleep deprivation. Prog Cardiovasc Dis 2009; 51(4): 294-302.

[8] Okun ML, Coussons-Read M, Hall M. Disturbed sleep is associated with increased C-reactive protein in young women. Brain Behav Immun 2009; 23(3): 351-4.

[9] Patel SR, Zhu X, Storfer-Isser A, et al. Sleep duration and biomarkers of inflammation. Sleep 2009; 32(2): 200-4.

[10] Van Cauter E, Holmback U, Knutson K, et al. Impact of sleep and sleep loss on neuroendocrine and metabolic function. Horm Res 2007; 67 Suppl 1:2-9.

[11] Dempsey JA, Veasey SC, Morgan BJ, O'Donnell CP. Pathophysiology of sleep apnea. Physiol Rev 2010; 90(1): 47-112.

[12] Biri A, Onan A, Devrim E, Babacan F, Kavutcu M, Durak I. Oxidant status in maternal and cord plasma and placental tissue in gestational diabetes. Placenta 2006; 27(2-3): 327-32.

[13] Challis JR, Lockwood CJ, Myatt L, Norman JE, Strauss JF, 3rd, Petraglia F. Inflammation and pregnancy. Reprod Sci 2009; 16(2): 206-15.

[14] Desoye G, Hauguel-de Mouzon S. The human placenta in gestational diabetes mellitus. The insulin and cytokine network. Diabetes Care 2007; 30(2): S120-6.

[15] Spiegel K, Leproult R, Van Cauter E. Impact of sleep debt on metabolic and endocrine function. Lancet 1999; 354(9188): 14359.

[16] Stamatakis K, Punjabi NM. Effects of Sleep Fragmentation on Glucose Metabolism in Normal Subjects. Chest 2009 137(1): 95101.

[17] Ayas NT, White DP, Al-Delaimy WK, et al. A prospective study of self-reported sleep duration and incident diabetes in women. Diabetes Care 2003; 26(2): 380-4.

[18] Beihl DA, Liese AD, Haffner SM. Sleep duration as a risk factor for incident type 2 diabetes in a multiethnic cohort. Ann Epidemiol 2009; 19(5): 351-7.

[19] Gangwisch JE, Heymsfield SB, Boden-Albala B, et al. Sleep duration as a risk factor for diabetes incidence in a large U.S. sample. Sleep 2007; 30(12): 1667-73.

[20] Gottlieb DJ, Punjabi NM, Newman AB, et al. Association of sleep time with diabetes mellitus and impaired glucose tolerance. Arch Intern Med 2005; 165(8): 863-7.

[21] Rafalson L, Donahue RP, Stranges S, et al. Short sleep duration is associated with the development of impaired fasting glucose: the Western New York Health Study. Ann Epidemiol 2010; 20(12): 883-9.

[22] Vgontzas AN, Liao D, Pejovic S, Calhoun S, Karataraki M, Bixler EO. Insomnia with objective short sleep duration is associated with type 2 diabetes: A population-based study. Diabetes Care 2009; 32(11): 1980-5.

[23] Yaggi HK, Araujo AB, McKinlay JB. Sleep duration as a risk factor for the development of type 2 diabetes. Diabetes Care 2006; 29(3): 657-61.

[24] Buxton OM, Marcelli E. Short and long sleep are positively associated with obesity, diabetes, hypertension, and cardiovascular disease among adults in the United States. Soc Sci Med 2010; 71(5): 1027-36.

Tuomilehto H, Peltonen M, Partinen M, et al. Sleep duration, lifestyle intervention, and incidence of type 2 diabetes in impaired glucose tolerance: The Finnish Diabetes Prevention Study. Diabetes Care 2009; 32(11): 1965-71.

[26] Hauri P, Ed The International Classification of Sleep Disorders, Diagnostic and Coding Manual. Westchester, IL: American Academy of Sleep Medicine; 2005. 
[27] Iber C, Ancoli-Israel S, Chesson A, Quan S. The AASM manual for the scoring of sleep and associated events: rules, terminology and technical specifications. Westchester, IL: American Academy of Sleep Medicine; 2007.

[28] Drager LF, Li J, Reinke C, Bevans-Fonti S, Jun JC, Polotsky VY. Intermittent Hypoxia Exacerbates Metabolic Effects of DietInduced Obesity. Obesity (Silver Spring) 2011; 19(11):2167-74.

[29] Iiyori N, Alonso LC, Li J, et al. Intermittent hypoxia causes insulin resistance in lean mice independent of autonomic activity. Am J Respir Crit Care Med 2007; 175(8): 851-7.

[30] Marshall NS, Wong KK, Phillips CL, Liu PY, Knuiman MW, Grunstein RR. Is sleep apnea an independent risk factor for prevalent and incident diabetes in the Busselton Health Study? J Clin Sleep Med 2009; 5(1): 15-20.

[31] Muraki I, Tanigawa T, Yamagishi K, et al. Nocturnal intermittent hypoxia and the development of type 2 diabetes: the Circulatory Risk in Communities Study (CIRCS). Diabetologia 2010; 53(3): 481-8.

[32] Reichmuth KJ, Austin D, Skatrud JB, Young T. Association of sleep apnea and type II diabetes: a population-based study. Am J Respir Crit Care Med 2005; 172(12): 1590-5.

[33] Stamatakis K, Sanders MH, Caffo B, et al. Fasting glycemia in sleep disordered breathing: lowering the threshold on oxyhemoglobin desaturation. Sleep 2008; 31(7): 1018-24.

[34] Aronsohn RS, Whitmore H, Van Cauter E, Tasali E. Impact of untreated obstructive sleep apnea on glucose control in type 2 diabetes. Am J Respir Crit Care Med 2010; 181(5): 507-13.

[35] Butte NF. Carbohydrate and lipid metabolism in pregnancy: normal compared with gestational diabetes mellitus. Am J Clin Nutr 2000; 71(5 Suppl): 1256S-61S.

[36] Homko CJ, Sivan E, Reece EA, Boden G. Fuel metabolism during pregnancy. Semin Reprod Endocrinol 1999; 17(2): 119-25.

[37] Creasy RK, Resnik R, Iams JD. Creasy and Resnik's MaternalFetal Medicine: Principles and Practice. $6^{\text {th }}$ ed. Philadelphia: Saunders 2009; pp. 953-94.

[38] ACOG technical bulletin. Diabetes and pregnancy. Number 200-December 1994 (replaces No. 92, May 1986). Committee on Technical Bulletins of the American College of Obstetricians and Gynecologists. Int J Gynaecol Obstet 1995; 48(3): 331-9.

[39] Metzger BE. Long-term outcomes in mothers diagnosed with gestational diabetes mellitus and their offspring. Clin Obstet Gynecol 2007; 50(4): 972-9.

[40] Facco FL, Grobman WA, Kramer J, Ho KH, Zee PC. Self-reported short sleep duration and frequent snoring in pregnancy: impact on glucose metabolism. Am J Obstet Gynecol 2010; 203(2): 142.e1-5.
[41] Qiu C, Enquobahrie D, Frederick IO, Abetew D, Williams MA. Glucose intolerance and gestational diabetes risk in relation to sleep duration and snoring during pregnancy: a pilot study. BMC Womens Health 2010; 10: 17.

[42] Reutrakul S, Zaidi N, Wroblewski K, et al. Sleep Disturbances and Their Relationship to Glucose Tolerance in Pregnancy. Diabetes Care 2011; 34(11): 2454-7.

[43] Lauderdale DS, Knutson KL, Yan LL, Liu K, Rathouz PJ. Selfreported and measured sleep duration: how similar are they? Epidemiology 2008; 19(6): 838-45.

[44] Bourjeily G, Raker CA, Chalhoub M, Miller MA. Pregnancy and fetal outcomes of symptoms of sleep-disordered breathing. Eur Respir J 2010; 36(4): 849-55.

[45] Olivarez SA, Ferres M, Antony K, et al. Obstructive sleep apnea screening in pregnancy, perinatal outcomes, and impact of maternal obesity. Am J Perinatol 2011; 28(8): 651-8.

[46] O'Brien LM, Bullough AS, Owusu JT, et al. Pregnancy-onset habitual snoring, gestational hypertension, and preeclampsia: prospective cohort study. Am J Obstet Gynecol 2012; 207(6): 487.e1-9.

[47] Abrishami A, Khajehdehi A, Chung F. A systematic review of screening questionnaires for obstructive sleep apnea. Can J Anaesth 2010; 57(5): 423-38.

[48] Johns MW. Reliability and factor analysis of the Epworth Sleepiness Scale. Sleep 1992; 15(4): 376-81.

[49] Olivarez SA, Maheshwari B, McCarthy M, et al. Prospective trial on obstructive sleep apnea in pregnancy and fetal heart rate monitoring. Am J Obstet Gynecol 2010; 202(6): 552.e1-7.

[50] Facco FL, Ouyang DW, Zee PC, Grobman WA. Development of a pregnancy specific screening tool for sleep apnea. J Clin Sleep Med 2012; 15;8(4):389-94.

[51] Bliwise DL, Nekich JC, Dement WC. Relative validity of selfreported snoring as a symptom of sleep apnea in a sleep clinic population. Chest 1991; 99(3): 600-8.

[52] Facco FL. Sleep-disordered breathing and pregnancy. Semin Perinatol 2011; 35(6): 335-9.

[53] Chen YH, Kang JH, Lin CC, Wang IT, Keller JJ, Lin HC. Obstructive sleep apnea and the risk of adverse pregnancy outcomes. Am J Obstet Gynecol 2012; 206(2): 136.e1-5.

[54] Facco FL, Liu CS, Cabello AA, Kick A, Grobman WA, Zee PC. Sleep-disordered breathing: a risk factor for adverse pregnancy outcomes? Am J Perinatol 2012; 29(4): 277-82. 